\title{
HIGH-GRADE VERSUS LOW-GRADE SEROUS CARCINOMA OF THE OVARY - CURRENT DIFFERENTIAL DIAGNOSIS AND PERSPECTIVES
}

\author{
Manuela POPA ${ }^{1 凶}$, Adelina BIRCEANU COROBEA ${ }^{2}$, Octavian MUNTEANU ${ }^{3}$, Monica M. \\ CIRSTOIU $^{3}$, Maria SAJIN ${ }^{1}$ \\ ${ }^{1}$ Department of Pathology, „Carol Davila“ University of Medicine and Pharmacy, University Emergency \\ Hospital, Bucharest, Romania \\ 2 Department of Pathology, „Sfanta Maria“ Clinical Hospital, Bucharest, Romania \\ ${ }^{3}$ Department of Obstetrics and Gynecology, University Emergency Hospital, Bucharest, Romania
}

Received 11 Oct 2018, Accepted 30 Nov 2018

https://doi.org/10.31688/ABMU.2018.53.4.11

\section{Abstract}

Introduction. Serous carcinoma is responsible for $47 \%$ of all ovarian cancers, and from these cases, only $5 \%$ are represented by low-grade serous carcinoma, the rest of them accounting for high-grade serous carcinoma.

Objective. The aim of this study is an observational approach of the differences and similarities of the two types of serous carcinoma of the ovary, that must be seen as different forms of cancer and rendered with care.

Methods. We performed a retrospective study using three cases of ovarian high-grade serous carcinoma and three cases of ovarian low-grade serous carcinoma, diagnosed at the University Emergency Hospital Bucharest. We analyzed patients' age, clinical symptoms, macroscopic and microscopic features together with immunohistochemistry tests.

Results. Mean age for $\mathrm{HG}$ carcinoma was 71.3 years old and for LG carcinoma 47.6 years old. Average tumor diameter was with $5.67 \mathrm{~cm}$ higher for LG carcinoma. The most encountered stage for HG tumors was $\mathrm{pT} 2 \mathrm{a}$ and for LG tumors was pT1a. Mean value

\section{Résumé}

Comparaison entre les deux types de carcinome séreux de l'ovaire, à haut et à bas degré-diagnostic différentiel courant et perspectives

Introduction. Le carcinome séreux est responsable de $47 \%$ de tous les cancers de l'ovaire. Parmi ces cas, 5\% seulement sont représentés par un carcinome séreux à bas degré, le reste d'entre eux représentant un carcinome séreux à haut degré.

Objectifs. Le but de cette étude est une approche observationnelle des différences et des similitudes entre les deux types de carcinome séreux de l'ovaire, qui doivent être considérés comme des formes différentes de cancer et traités avec précaution.

Méthodes. Nous avons réalisé une étude rétrospective utilisant trois cas de carcinome séreux ovarien à haut degré et trois cas de carcinome séreux à bas degré ovarien, diagnostiqués à l'Hôpital Universitaire d'Urgence de Bucarest. Nous avons analysé l'âge des patients, les symptômes cliniques, les caractéristiques 
for Ki67 was with $36.33 \%$ higher for HG carcinoma. AR expressed diffuse positivity in two cases of LG and only focal positivity in two cases of HG. CD44 expressed focal positivity in all cases of LG and had different patterns in $\mathrm{HG}$.

Conclusions. We found considerable differences between patients' mean age, macroscopic and microscopic features, together with immunohistochemistry expression for Ki67, AR, CD44.

Keywords: high-grade serous carcinoma, low-grade serous carcinoma, AR, CD44.

\author{
Abbreviation list \\ $\mathrm{AR}=$ androgen receptor \\ $\mathrm{BRAF}=$ human gene that encodes a protein called B-Raf \\ CD44 = cluster of differentiation 44 \\ $\mathrm{ER}=$ estrogen receptor \\ HER2 = human epidermal growth factor receptor 2 \\ $\mathrm{HG}=$ high-grade \\ Ki67 $=$ Anti-human Ki-67 Antibody $=$ proliferation index \\ KRAS $=$ a gene that acts as an on/off switch in cell sig- \\ naling, first identified as an oncogene in Kirsten RAt \\ Sarcoma virus \\ $\mathrm{LG}=$ low-grade \\ MAPK $=$ mitogen-activated protein kinase \\ $\mathrm{p} 53=$ tumor protein $\mathrm{p} 53$, encoded by tumor suppression \\ gene TP53 \\ $\mathrm{Pi} 3 \mathrm{~K} / \mathrm{mTOR}=$ intracellular signaling pathway \\ Phosphatidylinositol-4,5-bisphosphate 3-kinase/mam- \\ malian target of rapamycin \\ $\mathrm{Rb} 1=$ retinoblastoma protein \\ $\mathrm{WHO}=$ World Health Organization \\ WT1 = Wilms tumor protein, encoded by WT1 gene
}

\section{INTRODUCTION}

Ovarian cancer represents the $5^{\text {th }}$ cause of cancer and the $5^{\text {th }}$ cause of death due to cancer in females in the European Union ${ }^{1}$. Serous carcinoma is responsible for $47 \%$ of all ovarian cancers, and from these cases, only 5\% are represented by low-grade serous carcinoma, the rest of them accounting for high-grade serous carcinoma ${ }^{2,3}$. The separation of these two entities has started even from 2004, but was officially stated as different reporting system worldwide when 2014 edition of WHO Classification of Tumors of the Female Reproductive Organs appeared ${ }^{2,4,5}$. They are considered two forms of cancer with different biological behavior and outcome ${ }^{6}$. Because the low-grade tumors are rare, their differences in origin and development are not fully understood ${ }^{2,6}$. macroscopiques et microscopiques ainsi que les tests d'immunohistochimie.

Résultats. L'âge moyen du carcinome à $\mathrm{HG}$ était de 71,3 ans et celui du carcinome à LG à 47,6 ans. Le diamètre moyen de la tumeur était supérieur de 5,67 $\mathrm{cm}$ pour le carcinome LG. Le stade le plus rencontré pour les tumeurs HG était le pT2a et pour les tumeurs LG était le pT1a. La valeur moyenne pour Ki67 était de 36,33\% plus élevée pour le carcinome HG. AR a exprimé une positivité diffuse dans deux cas de LG et une positivité focale dans deux cas de HG. La CD44 exprimait une positivité focale dans tous les cas de LG et présentait des profils différents de HG.

Conclusions. Nous avons trouvé des différences considérables entre l'âge moyen des patients, leurs caractéristiques macroscopiques et microscopiques, ainsi que l'expression immunohistochimique de Ki67, AR, CD44.

Mots-clés: carcinome séreux à haut degré, carcinome séreux à bas degré, AR, CD44.

\section{The OBJective OF THE STUdY}

We performed an observational study on the differential diagnosis between the two types of serous carcinoma of the ovary with current and new perspectives on the approach of these malignancies.

\section{Material AND MEthods}

We performed a retrospective study using three cases of high-grade (HG) serous carcinoma and three cases of ovarian low-grade (LG) serous carcinoma, diagnosed at the University Emergency Hospital Bucharest, Romania. We used hospital's data base and pathology department records for clinical information and macroscopic features such as: tumor diameter, solid/cystic component, tumor extension, lymph node status; using hematoxylin-eosin stains we analyzed the microscopic 
features: solid area growth, papillary formation, mitotic count, presence of necrosis. We performed immunohistochemistry tests on archived paraffin-embedded tissue blocks: WT1, p53, Ki67, ER, AR, CD44.

\section{Results AND DISCUSSIONS}

The mean age of patients with high-grade serous carcinoma was 71.3 years old and of patients with low-grade serous carcinoma 47.6 years old (Figure 1). In the literature, we found a lower mean age, of 57-63 years old for $\mathrm{HG}$ carcinoma and 42 years old for $\mathrm{LG}$ carcinoma $^{7}$ (Figure 1). All patients, except one case of high-grade carcinoma, had urban home environment.

The average tumor diameter was of $8.83 \mathrm{~cm}$ for HG tumors and of $14.5 \mathrm{~cm}$ for LG tumors, with 5.67 $\mathrm{cm}$ higher for LG carcinoma. The most encountered stage for HG carcinomas was pT2a (66.6\%) and for LG carcinomas was pT1a (66.6\%).

On macroscopic examination, high-grade carcinomas have a predominant solid growth (Figure 2), with evident hemorrhage and necrosis and smaller quantities of serous fluid than low-grade carcinomas, which are predominantly cystic tumors, with small to medium vegetations that correspond to papillary growth with invasive areas (Figure 3).



Figure 1. Mean age of patients with ovarian serous carcinoma

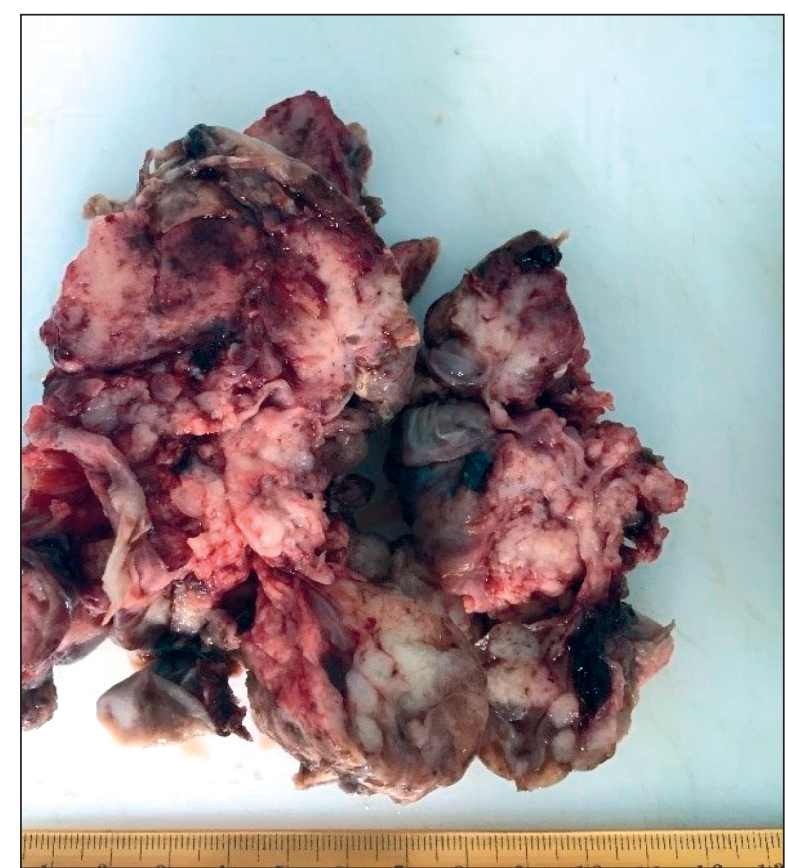

Figure 2. Macroscopic appearance of ovarian high-grade serous carcinoma

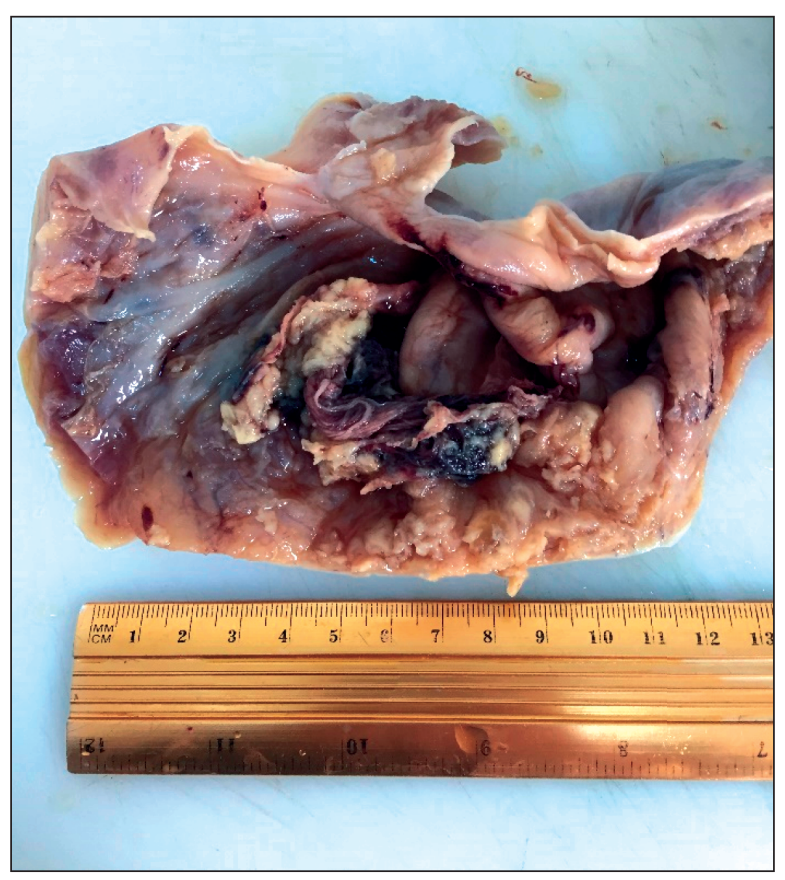

Figure 3. Macroscopic appearance of ovarian low-grade serous carcinoma 




Figure 4. Average Ki67 index in ovarian serous carcinoma

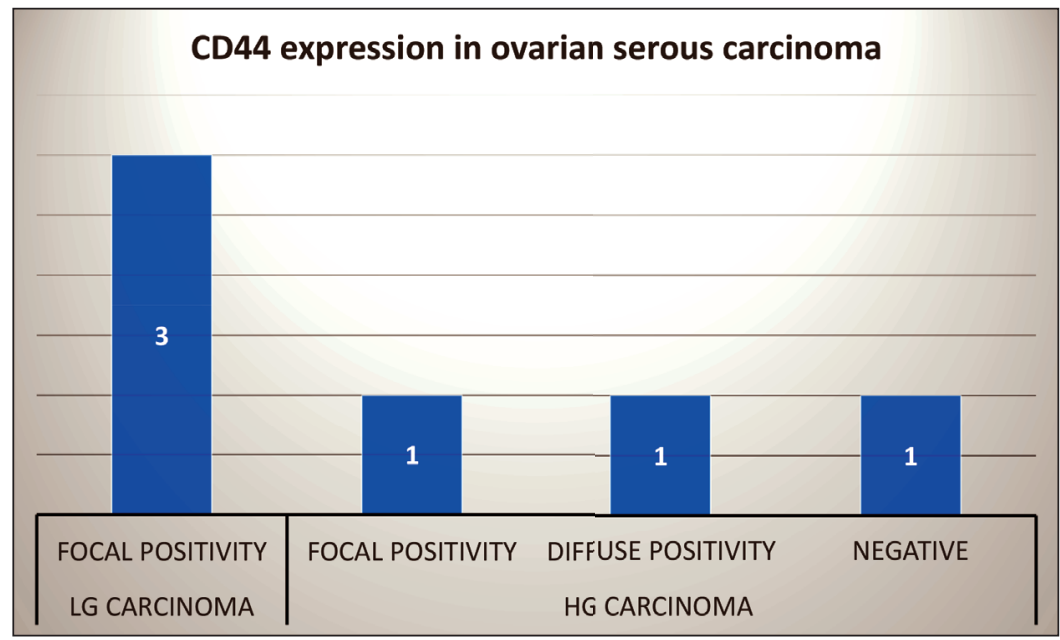

Figure 5. CD44 expression in ovarian serous carcinoma

On histopathological examination, high-grade tumors have predominantly solid areas of severe atypical cells, mitotic count over 30 mitosis/10HPF (high power field) and large areas of necrosis, whereas low-grade tumors have papillary and micropapillary architecture, mitotic count under 15 mitosis/10HPF and rare focal areas of necrosis.

Lymph node status could be evaluated in two cases of high-grade serous carcinoma (one case with lymph node metastasis and the other free of invasion) and in only one case of low-grade serous carcinoma (free of invasion). Lymph node sampling and taking blind peritoneal biopsies are important in surgical staging of early ovarian cancer and involvement of only para-aortic lymph nodes in advanced stage results in a better chance of survival than involvement of pelvic lymph nodes only or both pelvic and para-aortic lymph nodes simultaneously ${ }^{8,9}$.

The mean value for $\mathrm{Ki} 67$ index was $76.6 \%$ for HG carcinoma and $40.3 \%$ for LG carcinoma, with 36.33\% higher for HG group (Figure 4). However, we found one study in the literature where expressions of p53 and $\mathrm{Ki} 67$ were found to have little correlation with overall survival and disease-free survival ${ }^{10}$.

WT1 (Wilms Tumor protein 1), p53 were positive for both categories, and ER (estrogen receptor) was positive over $80 \%$ for $66.6 \%$ of each group. WT1 and p53 showed previous success for use in small biopsy specimens from extraovarian sites due to little variability between ovarian and omental sites $^{11}$. In their study of sex steroid hormone receptors expressed in ovarian carcinomas, Gomora MJ 
et al found a high frequency of ER negative $\mathrm{HG}$ carcinoma ${ }^{12}$. However, other studies confirmed ER positivity in these tumors, associated with recurrent disease and peritoneal metastasis ${ }^{13}$. Also, other studies stated that LG tumors have higher ER and PR expression compared to HG tumors and that estrogen receptor expression was associated with increased risk of lympho-vascular space invasion ${ }^{14,15}$.

Mutation of TP53 gene is the most frequent genomic alteration of high-grade carcinomas, while KRAS and BRAF mutations are more likely encountered in low-grade ones ${ }^{2,16,17}$. In one study DNA derived from tumor was detected in the vaginas of $60 \%$ of patients with ovarian cancer with intact fallopian tubes and harbored the exact same TP53 mutation $^{18}$. Other frequent mutations but poorly understood are RB1 (retinoblastoma) deletions in high-grade serous carcinoma ${ }^{19}$. Compared to other localizations, alteration in PI3K/mTOR, MAPK pathways and HER2 expression/amplification is more frequent in uterine serous carcinoma than in ovarian serous carcinoma ${ }^{20}$.

AR expressed diffuse positivity in two cases of LG and only focal positivity in two cases of HG. In the literature, reported cases expressed androgen receptor in $47.5 \%$ of serous carcinomas, but with lower value compared with benign and borderline disease and suggested that AR signaling capacity may be reduced with the development but not metastatic progression of serous ovarian cancer ${ }^{21,22}$.

CD44 is a glycoprotein receptor activated by hyaluronic acid, with role in cell to cell adhesion and recently described as a stem cell marker, reported positive in the majority of epithelial ovarian cancer and correlated with advance stage disease and unfavorable 5-year prognosis ${ }^{23,24}$. CD44 expressed focal positivity in all cases of LG carcinoma (100\%) and had different patterns in HG carcinoma (Figure 5).

Prognosis of low-grade serous ovarian carcinoma shows favorable overall survival, compared to general ovarian cancer population, but is suspicious of resistance to conventional treatments ${ }^{25}$. Some studies suggest that mitogen-activated protein kinase (MAPK) inhibitor and MAPK mutations might eventually be useful in guiding treatment ${ }^{26}$.

While most high-grade ovarian serous carcinomas are highly sensitive and can benefit of cytoreductive surgery and platinum and taxane-based chemotherapy, the majority of patients experience recurrence of treatment-resistant tumors ${ }^{27}$. Bohm S et al developed a chemotherapy response score system and applied it to an independent validation cohort of HG patients ${ }^{28}$. That is why further characterization of immunomodulatory factors are required in developing immune checkpoint therapies. The tumor microenvironment of $\mathrm{HG}$ tumors was stated to have other important elements that may influence treatment response, including fibroblasts, endothelial cells and the extracellular matrix ${ }^{29}$.

Although a dual pathway of ovarian serous carcinogenesis has been proposed, cases of coexistence of low-grade and high-grade carcinoma in the same patient have been reported, and even accompanied by undifferentiated carcinoma, regarded as a possible form of dedifferentiation ${ }^{30}$. That is why ovarian serous carcinoma is a very complex spectrum of disease and it should be rendered with care by medical staff.

\section{Conclusions}

We found considerable differences between patients' mean age, macroscopic and microscopic features, together with immunohistochemistry expression for Ki67, AR and CD 44 markers of the two groups represented by high-grade and low-grade carcinoma, respectively. The differential diagnosis is important because tumor's biological characteristics and behavior are different, and with the help of new perspective markers we can further study possible correlations and take into consideration novel therapeutic targets.

\section{Acknowledgements:}

All the authors contributed equally to the study and take responsibility for the integrity of the data and the accuracy of the data analysis.

\section{Compliance with Ethics Requirements:}

"The authors declare that all the procedures and experiments of this study respect the ethical standards in the Helsinki Declaration of 1975, as revised in 2008(5), as well as the national law. Informed consent was obtained from all the patients included in the study"

"The authors declare no conflict of interest regarding this article"

\section{References}

1. Ferlay J, Steliarova-Foucher E, Loertet-Tieulent J, et al. Cancer incidence and mortality patterns in Europe: estimates for 40 countries in 2012. Eur J Cancer 2013; 49:1374403.

2. Kurman RJ, Carcangiu ML, Herrington CS, Young RH. WHO classification of tumors of female reproductive organs. 4th Ed Lyon, IARC; 2014:8-86.

3. Kumar V, Abbas AK, Aster JC. Robbins and Cotran Pathologic Basis of Disease. Ninth Edition. Saunders Elsevier 2015. ISBN 978-0-8089-2450-0. 
4. Malpica A, Deavers MT, Lu K et al. Grading ovarian serous carcinoma using a two-tier system. Am J Surg Pathol 2004;28(4):496-504.

5. Shih IeM, Kurman RJ. Ovarian tumorigenesis: a proposed model based on morphological and molecular genetic analysis. Am J Pathol 2004, 164:1511-1518.

6. Vang R, Shih IeM, Kurman RJ. Ovarian low-grade and high-grade serous carcinoma: pathogenesis, clinicopathologic and molecular biologic features, and diagnostic problems. Adv Anat Pathol 2009;16(5):267-82.

7. Kurman RJ, Ellenson LH, Ronnett B. Blaustein's Pathology of the Female Genital Tract. Sixth Edition, Springer Science+Business Media, LLC 2011. e-ISBN: 978-1-4419-0489-8.

8. Timmers PJ, Zwinderman K, Coens C, et al. Lymph node sampling and taking of blind biopsies are important elements of the surgical staging of early ovarian cancer. Int $J$ Gynecol Cancer 2010;20(7):1142-7.

9. Gasimli K, Braicu EI, Nassir M, et al. Lymph node involvement pattern and survival differences of FIGO IIIC and FIGO IIIA1 ovarian cancer patients after primary complete tumor debulking surgery: a 10-year retrospective analysis of the Tumor Bank Ovarian Cancer Network. Ann Surg Oncol 2016;23(4):1279-86.

10. Shen XX, Yu L, Bi R, et al. Clinicopathologic study and immunohistochemistry comparison of Pax2, p53 and Ki-67 in low- and high-grade ovarian serous carcinomas. Zhonghua Bing Li Xue Za Zhi 2011;40(8):511-6.

11. Köbel M, Turbin D, Kalloger SE, et al. Biomarker expression in pelvic high-grade serous carcinoma: comparison of ovarian and omental sites. Int J Gynecol Pathol 2011;30(4):366-71.

12. Gomora MJ, Morales-Vasquez F, Pedernera E, et al. Sexual steroid hormone receptors profiles in ovarian carcinoma in Mexican women. Endocr Connect 2018;pii: EC-18-0158. doi: 10.1530/EC-18-0158.

13. Chen S, Dai X, Gao Y, et al. The positivity of estrogen receptor and progesterone receptor may not be associated with metastasis and recurrence in epithelial ovarian cancer. Sci Rep 2017; 7(1):16922.

14. Escobar J, Klimowicz AC, Dean M, et al. Quantification of ER/PR expression in ovarian low-grade serous carcinoma. Gynecol Oncol 2013;128(2):371-6.

15. Matsuo K, Sheridan TB, Mabuchi S, et al. Estrogen receptor expression and increased risk of lymphovascular space invasion in high-grade serous ovarian carcinoma. Gynecol Oncol 2014;133(3):473-9

16. Ab Mutalib NS, Syafruddin SE, Md Zain RR, et al. Molecular characterization of serous ovarian carcinoma using a multigene next generation sequencing cancer panel approach. BMC Res Notes 2014;7:805.
17. McAlpine JN, Porter $\mathrm{H}$, Köbel M, et al. BRCA1 and BRCA2 mutations correlate with TP53 abnormalities and presence of immune cell infiltrates in ovarian high-grade serous carcinoma. Mod Pathol 2012;25(5):740-50.

18. Erickson BK, Kinde I, Dobbin ZC, et al. Detection of somatic TP53 mutations in tampons of patients with high-grade serous ovarian cancer. Obstet Gynecol 2014;124(5):881-5.

19. Milea A, George SH, Matevski D, et al. Retinoblastoma pathway deregulatory mechanisms determine clinical outcome in high-grade serous ovarian carcinoma. Mod Pathol 2014;27(7):991-1001

20. Mahdi H, Xiu J, Reddy SK, et al. Alteration in PI3K/mTOR, MAPK pathways and Her2 expression/amplification is more frequent in uterine serous carcinoma than ovarian serous carcinoma. J Surg Oncol 2015;112(2):188-94.

21. Lee P, Rosen DG, Zhu C, e al. Expression of progesterone receptor is a favorable prognostic marker in ovarian cancer. Gynecol Oncol 2005; 96(3):671-7.

22. Butler MS, Ricciardelli C, Tilley WD, et al. Androgen receptor protein levels are significantly reduced in serous ovarian carcinomas compared with benign or borderline disease but are not altered by cancer stage or metastatic progression. Horm Cancer 2013; 4(3):154-64.

23. Sacks JD, Barbolina MV. Expression and function of CD44 in epithelial ovarian carcinoma. Biomolecules 2015; 5(4): 3051-3066.

24. Lin J, Ding D. The prognostic role of the cancer stem cell marker CD44 in ovarian cancer: a meta-analysis. Cancer Cell Int 2017;17:8.

25. Della Pepa C, Tonini G, Santini D, et al. Low grade serous ovarian carcinoma: from the molecular characterization to the best therapeutic strategy. Cancer Treat Rev 2015;41(2):136-43

26. Kaldawy A, Segev Y, Lavie O, et al. Low-grade serous ovarian cancer: A review. Gynecol Oncol 2016;143(2):433-438.

27. Castellarin M, Milne K, Zeng T, et al. Clonal evolution of high-grade serous ovarian carcinoma from primary to recurrent disease. J Pathol 2013;229(4):515-24.

28. Böhm S, Faruqi A, Said I et al. Chemotherapy response score: development and validation of a system to quantify histopathologic response to neoadjuvant chemotherapy in tubo-ovarian high-grade serous carcinoma. J Clin Oncol 2015;33(22):2457-63.

29. Bowtell DD, Böhm S, Ahmed AA, et al. Rethinking ovarian cancer II: reducing mortality from high-grade serous ovarian cancer. Nat Rev Cancer 2015;15(11):668-79.

30. Boyd C, McCluggage WG. Low-grade ovarian serous neoplasms (low-grade serous carcinoma and serous borderline tumor) associated with high-grade serous carcinoma or undifferentiated carcinoma: report of a series of cases of an unusual phenomenon. Am J Surg Pathol 2012;36(3):368-75. 